\title{
A nested real-time PCR assay for the quantification of Plasmodium falciparum DNA extracted from dried blood spots
}

\author{
Tuan M Tran ${ }^{1 * \dagger}$, Amirali Aghili ${ }^{1 \dagger}$, Shanping $\mathrm{Li}^{1}$, Aissata Ongoiba ${ }^{2}$, Kassoum Kayentao ${ }^{2}$, Safiatou Doumbo ${ }^{2}$,
} Boubacar Traore ${ }^{2}$ and Peter D Crompton ${ }^{1}$

\begin{abstract}
Background: As public health efforts seek to eradicate malaria, there has been an emphasis on eliminating low-density parasite reservoirs in asymptomatic carriers. As such, diagnosing submicroscopic Plasmodium infections using PCR-based techniques has become important not only in clinical trials of malaria vaccines and therapeutics, but also in active malaria surveillance campaigns. However, PCR-based quantitative assays that rely on nucleic acid extracted from dried blood spots (DBS) have demonstrated lower sensitivity than assays that use cryopreserved whole blood as source material.

Methods: The density of Plasmodium falciparum asexual parasites was quantified using genomic DNA extracted from dried blood spots (DBS) and the sensitivity of two approaches was compared: quantitative real-time PCR (qPCR) targeting the $P$. falciparum 18 sibosomal RNA gene, either with an initial conventional PCR amplification prior to $\mathrm{GPCR}$ (nested $\mathrm{qPCR}$ ), or without an initial amplification (qPCR only). Parasite densities determined by nested qPCR, qPCR only, and light microscopy were compared.

Results: Nested qPCR results in 10-fold higher sensitivity ( 0.5 parasites/ $\mu$ l) when compared to qPCR only (five parasites/ul). Among microscopy-positive samples, parasite densities calculated by nested qPCR correlated strongly with microscopy for both asymptomatic (Pearson's $r=0.58, P<0.001$ ) and symptomatic (Pearson's $r=0.70, P<0.0001$ ) P. falciparum infections.

Conclusion: Nested qPCR improves the sensitivity for the detection of $P$. falciparum blood-stage infection from clinical DBS samples. This approach may be useful for active malaria surveillance in areas where submicroscopic asymptomatic infections are prevalent.
\end{abstract}

Keywords: Plasmodium falciparum, Nucleic acid testing, Quantitative PCR, Nested PCR, Dried blood spot, Passive surveillance

\section{Background}

Although light microscopy examination of peripheral blood smears remains the gold standard for malaria diagnosis and enumerating Plasmodium parasites, more sensitive molecular techniques that amplify parasite DNA using polymerase chain reaction (PCR) are routinely applied in clinical studies and epidemiological surveys for

\footnotetext{
* Correspondence: tuan.tran@nih.gov

${ }^{+}$Equal contributors

'Laboratory of Immunogenetics, National Institute of Allergy and Infectious Diseases, National Institutes of Health, Twinbrook 2, Room 125, 12441

Parklawn Drive, Rockville, Maryland 20852, USA

Full list of author information is available at the end of the article
}

the detection and monitoring of low-density, submicroscopic infections [1,2]. Moreover, sensitive diagnostic assays are becoming increasingly important as malaria eradication efforts seek to eliminate asymptomatic infections that serve as reservoirs for transmission $[3,4]$.

Quantification of low-density infections allows for determination of parasite growth dynamics in semi-immune individuals [5] or in the context of controlled human malaria infection during clinical vaccine trials $[2,5-7]$. Such studies have employed quantitative real-time PCR (qPCR) assays that have a detection limit of 0.02-0.06 parasites per $\mu \mathrm{l}$ but required extraction of DNA from at least $50 \mu \mathrm{l}$ 
of cryopreserved whole blood $[2,4,8]$, an inconvenient requirement for routine field studies. In contrast, dried filter paper blood spots (DBS) have been a practical way to archive parasite DNA for future analysis without the need for cryopreservation in field settings. Prior studies have shown that quantitative real-time PCR (qPCR) techniques using genomic DNA obtained from DBS samples can reliably detect only $\sim 4$ to 40 parasites per $\mu \mathrm{l}[9,10]$, which is only a modest improvement in sensitivity relative to thick-smear microscopy. Improving the ability to quantify low-density blood-stage infections would be beneficial, especially in studies in endemic areas where asymptomatic infections are common and often submicroscopic. The present study describes an approach that combines nested PCR with qPCR to increase the sensitivity to detect and quantify parasite DNA extracted from clinical DBS samples by at least one order of magnitude over existing qPCR-only methods.

\section{Methods \\ Ethics}

Clinical samples used in this study were obtained from an ongoing prospective, cohort study of malaria immunity in Kalifabougou, Mali that began in May 2011. The details of this cohort have been previously described [9]. The Ethics Committee of the Faculty of Medicine, Pharmacy, and Dentistry at the University of Sciences, Techniques, and Technology of Bamako and the Institutional Review Board of the National Institute of Allergy and Infectious Diseases, National Institutes of Health approved this study (NIAID IRB Protocol \# 11-I-N126). Written, informed consent was obtained from adult participants and from the parents or guardians of participating children before screening and enrollment.

\section{Study design and sample collection}

Blood samples in this study were obtained during passive and active malaria surveillance visits (occurring every two weeks) in Kalifabougou from May 2011 to December 2011 as previously described [9]. For each participant, peripheral blood was collected by fingerprick for 1) DBS samples archived on 903 Protein Saver filter paper (Whatman) and stored at $25^{\circ} \mathrm{C}$ with silica desiccant in sealed foil envelopes and 2) thick blood smears. Blood smears were stained with Giemsa, and P. falciparum parasites were counted against 300 leukocytes. Parasite densities were recorded as the number of asexual parasites/ $\mu \mathrm{l}$ of whole blood based on an average leukocyte count of 7500 cells/ $\mu \mathrm{L}$. During symptomatic visits, contemporaneous blood smears were performed for malaria diagnosis and appropriate treatment was initiated per the National Malaria Control Programme guidelines in Mali. Symptoms that initiated a diagnostic evaluation for malaria included fever, chills, sweats, fatigue, headache, nausea, vomiting, and general malaise.

\section{Sample preparation}

Initial screening for $P$. falciparum infections was performed using a non-quantitative, nested PCR technique that detects parasite DNA directly from a 1-mm circular punch of DBS at a sensitivity of $\sim 1$ parasite/ $\mu$ l as previously described [9]. For each participant, blood-smear microscopy and non-quantitative, nested PCR were performed on blood samples in chronological order starting from the initial enrolment visit until the first $P$. falciparum infection was detected. For DBS samples identified as P. falciparum-positive by this initial screen, genomic DNA (gDNA) was extracted from three 3-mm circular punches containing uniform amounts of blood using the QIAmp DNA Mini kit (Qiagen) per the manufacturer's protocol with a final elution volume of $150 \mu \mathrm{l}$ of $\mathrm{AE}$ buffer. The extraction protocol was followed rigorously to ensure that the final DNA concentration reflected the maximum obtainable yield. Parasite density calibration standards were generated from 10-fold serial dilutions of purified plasmid DNA containing a single copy of the P. falciparum $18 \mathrm{~S}$ ribosomal RNA (rRNA; MRA-177, MR4, ATCC) [11] at concentrations of $10^{9}$ copies $/ \mu$ l down to $1 \mathrm{copy} / \mu$ l diluted in PCR-grade water and gDNA extracted from a DBS sample from a $P$. falciparum-infected patient with a known parasite density of $>500,000$ parasites $/ \mu \mathrm{l}$ as determined by light microscopy at concentrations of $\sim 500,000$ parasites $/ \mu$ l down to 0.05 parasites $/ \mu$ l diluted in water containing gDNA from an uninfected donor (henceforth referred to as "infected standard"). P. falciparum (3D7) gDNA was isolated from parasite cultures with $>4 \%$ parasitaemia at schizogony using the QIAmp DNA Mini kit. DNA concentrations were determined by spectrophotometry (Nanodrop Lite, Thermoscientific).

\section{Conventional PCR amplification followed by nested quantitative real-time PCR}

Primer sequences and references are listed in Table 1. Initial rounds of amplifications were performed in $25 \mu \mathrm{l}$ reactions containing $1 \mu \mathrm{l}$ of template DNA, $0.5 \mu \mathrm{M}$ of PLU5/ PLU6 forward and reverse primers, and 1x KAPA2G Fast HS Ready Mix (Kapa Biosystems). In a conventional thermocycler, the template DNA was denatured at $95^{\circ} \mathrm{C}$ for $5 \mathrm{~min}$, followed by 15 cycles of amplification $\left(95^{\circ} \mathrm{C}\right.$ for $30 \mathrm{~s}, 61^{\circ} \mathrm{C}$ for $30 \mathrm{~s}$, and $72^{\circ} \mathrm{C}$ for $1 \mathrm{~min}$ ) and a final extension at $72^{\circ} \mathrm{C}$ for $1 \mathrm{~min}$. A reaction using $1 \mu \mathrm{l}$ of PCR-grade water in lieu of template DNA was always included as a negative control in this first round of amplification.

For the second round of amplification, $1 \mu \mathrm{l}$ of the PCR product from the initial amplification was used as the template in a qPCR reaction ( $20 \mu \mathrm{l}$ final volume) containing $0.2 \mu \mathrm{M}$ FAL1/FAL2 forward and reverse primers and 1X Power SYBR Green Master Mix (Applied Biosystems). Reactions were performed in 384-well optical PCR plates on an Applied Biosystems 7900HT Fast Real-Time PCR 
Table 1 Primers used for nucleic acid amplification

\begin{tabular}{lll}
\hline Primer name & Sequence & Reference \\
\hline rPLU5 & 5' CCTGTTGTTGCCTTAAACTTC 3' & Snounou, G. et al. 1993 [12] \\
rPLU6 & 5' TTAAATTGTTGCAGTTAAAACG 3' & \\
rFAL1 & 5' TTAAACTGGTTGGGAAAACCAAATATATT 3' \\
rFAL2 & 5' ACACAATGAACTCAATCATGACTACCCGTC 3' & \\
Human GAPDH F2 & 5' CGACCACTTTGTCAAGCTCA 3' & Smith, P.H. et al. 2011 [13] \\
Human GAPDH R2 & 5' GGTGGTCCAGGGGTCTACT 3' \\
\hline
\end{tabular}

system per the manufacturer's recommended PCR parameters $\left(50^{\circ} \mathrm{C}\right.$ for $2 \mathrm{~min}, 95^{\circ} \mathrm{C}$ for $10 \mathrm{~min}$ followed by $40 \mathrm{cy}$ cles of amplification [melt at $95^{\circ} \mathrm{C}$ for $15 \mathrm{~s}$, anneal/extend at $60^{\circ} \mathrm{C}$ for $\left.1 \mathrm{~min}\right]$ ) with the addition of a dissociation stage for subsequent melting curve analysis. In addition, $1 \mu \mathrm{l}$ of serially diluted P. falciparum plasmid and infected standards were used as direct templates (i.e. without prior amplification) for $\mathrm{qPCR}$ reactions.

The nested qPCR protocol was originally tested using $10,15,20,25$, and 30 cycles for the initial amplification, with 15 cycles yielding the largest absolute difference in threshold cycle $(\mathrm{Ct})$ values between the sample with the lowest and highest gDNA dilutions. Each experimental run included, as Plasmodium negative controls, a no template control (PCR-grade water as noted above) and gDNA extracted from donors previously determined to be Plasmodium negative by PCR, and, as positive controls, P. falciparum (3D7) gDNA, and the serially diluted, infected standard. All samples were run in duplicate or triplicate. As a DNA extraction control, real-time PCR was also performed on gDNA extracted from DBS using the human GAPDH primers in lieu of FAL1/FAL2 primers (Table 1).

\section{Quality assurance using external DBS samples}

To validate the assay, the above protocol was run using gDNA extracted from DBS samples provided by an external laboratory and used in a recent study on quality assurance of Plasmodium PCR [14]. After determining calculated parasite densities using the protocol described herein, operators were un-blinded to the parasite densities calculated by the external laboratory, which employed a different qPCR protocol targeting the $P$. falciparum lactate dehydrogenase gene as previously described [15].

\section{Data analysis}

ABI PRISM 7900 SDS software (version 2.4; Applied Biosystems) was used to evaluate the amplification and dissociation curves and determine the $\mathrm{Ct}$ values. Statistical analyses were performed in Prism 6.0 (GraphPad). Parasite densities (parasites/ $\mu \mathrm{l}$ ) and starting copy number of $P$. falciparum $18 \mathrm{~S}$ rRNA plasmid from the standards were plotted against $\mathrm{Ct}$ values derived from the nested qPCR assay to generate standard curves. For all samples with "unknown" parasite concentrations, parasite densities were estimated from a regression line fit to the linear part of the standard curves using the average of nested qPCRderived Ct values (performed in duplicate for all samples). The strength and significance of correlations were assessed with the Pearson's correlation coefficient.

\section{Results}

Standard curves plotting Ct values against starting copy numbers or parasite densities (parasites/ $\mu \mathrm{l}$ ) were generated from serially diluted plasmid DNA containing the P. falciparum $18 \mathrm{~S}$ rRNA gene or infected standard, respectively, for both 1) 15-cycle standard PCR amplification followed by nested qPCR and 2) amplification by qPCR only (Figure 1). Based on an estimate of 6 copies of $18 \mathrm{~S}$ rRNA per $P$. falciparum genome [10], the limit of detection using $P$. falciparum $18 \mathrm{~S}$ rRNA plasmid is 0.17 parasites/ $\mu \mathrm{l}$ (equivalent to $1 \mathrm{copy} / \mu \mathrm{l}$ ) for nested qPCR and 17 parasites/ $\mu$ l copies by qPCR only (equivalent to 100 copies/ $\mu$ l; Figures $1 \mathrm{~A}$ and $2 \mathrm{~A}$ ). Similarly, the limit of detection using infected standards is 0.05 parasites $/ \mu \mathrm{l}$ for nested $\mathrm{qPCR}$ and five parasites/ $\mu$ l for $\mathrm{qPCR}$ only (Figures $1 \mathrm{~B}$ and $2 \mathrm{~B}$ ). To evaluate whether the two different sources of template DNA ( $P$. falciparum $18 \mathrm{~S}$ rRNA plasmid versus infected standard) yielded directly comparable parasite density estimates based on their $\mathrm{Ct}$ values, the $\mathrm{Ct}$ values generated by nested qPCR were plotted against the parasite densities estimated from copy number for $P$. falciparum 18S rRNA plasmid or corresponding to the dilutions in the case of infected standards (Figure 1C). A strong, negative correlation existed between parasite density and $\mathrm{Ct}$ values when values from both sources were combined (Pearson's $\mathrm{r}-0.99 ; 95 \%$ CI $[-1.0$ to -0.96$]$; $P<0.001$ ). High $C t$ values (>33 cycles) generated in samples with no template during the first amplification (Figure 2A) were confirmed as negative by inspection of dissociation curves (Additional file 1).

Parasite densities derived from nested qPCR were correlated to parasite densities determined by microscopy of concurrent blood smears for smear-positive patients who were either symptomatic or asymptomatic at the time of DBS collection (Figure 3). Parasite densities calculated by nested PCR correlated strongly with both asymptomatic (Pearson's $r=0.58,95 \%$ CI [0.29 to 0.77], 


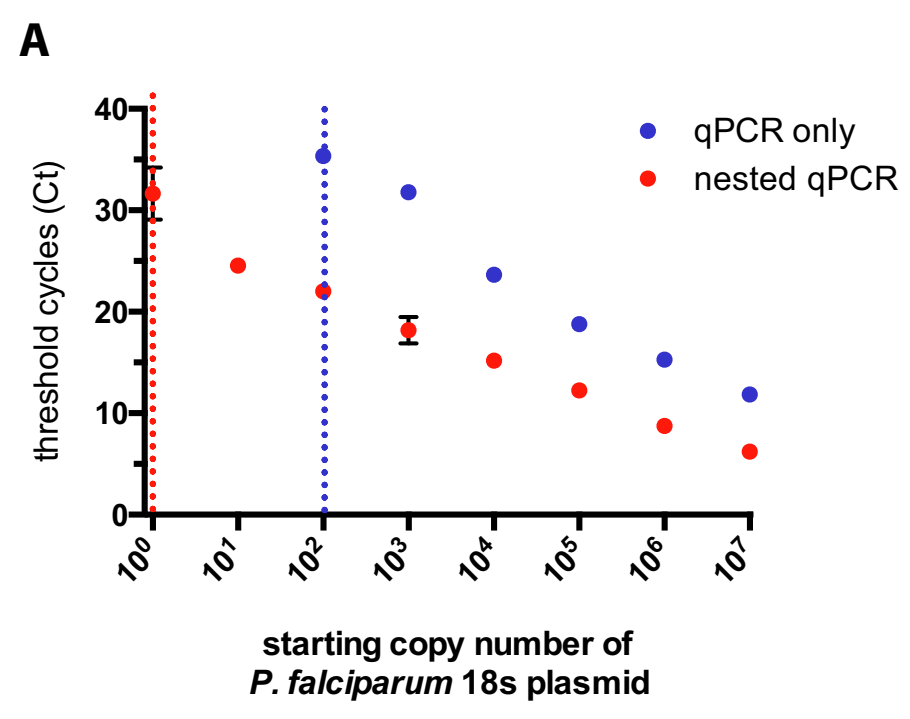

B

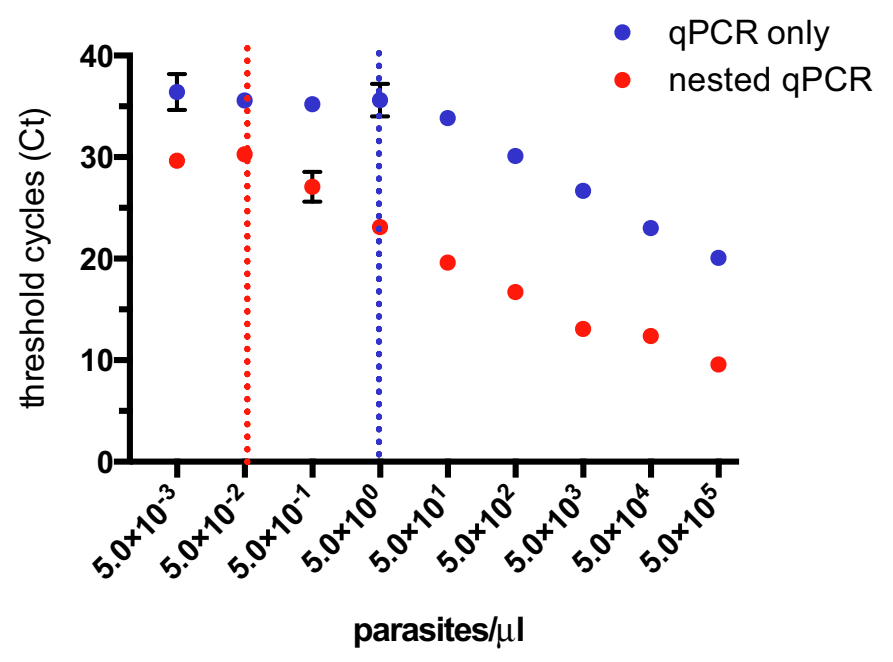

C

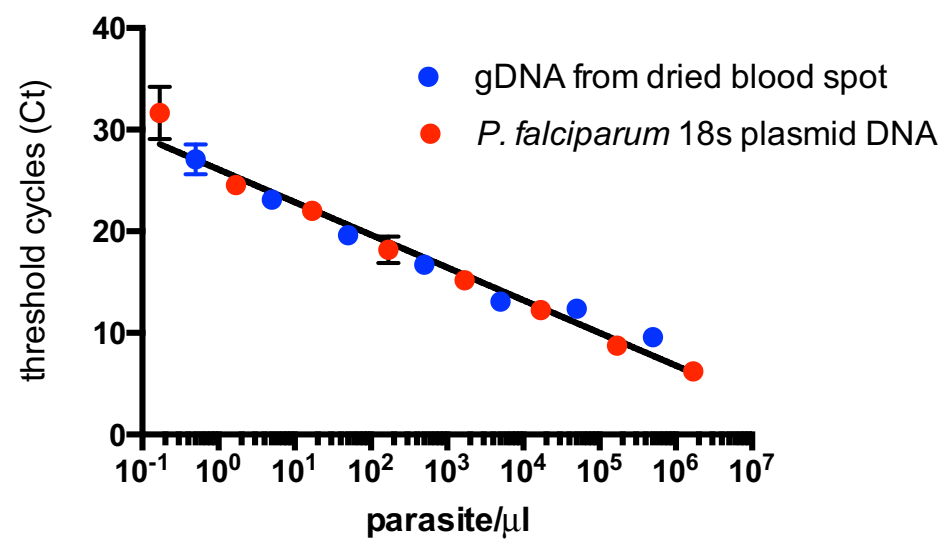

Figure 1 (See legend on next page.) 
(See figure on previous page.)

Figure 1 Comparison of quantitative real-time PCR standard curves. 10-fold plasmid or gDNA dilutions were plotted against Ct values generated from qPCR only and nested qPCR assays using (A) P. falciparum 18S rRNA plasmid or (B) gDNA extracted from dried blood spots obtained from a subject with clinical malaria as template DNA (described in the Methods). Points represent the mean of technical duplicates and error bars (where visible) indicate the standard deviation. Dotted lines represent the technical limit of detection as defined as the lowest template concentration for which there is a linear relationship between Ct values and copy number/parasite density. For (C), Ct values generated by nested qPCR were plotted against the parasite densities estimated from copy number for $P$. falciparum $18 \mathrm{~S}$ rRNA plasmid or corresponding to the dilutions from the clinical DBS standards. The best-fit regression line is shown as a black line.

$\mathrm{P}<0.001$ ) and symptomatic (Pearson's r 0.70 , 95\% CI [0.53 to 0.81], $\mathrm{P}<0.0001)$ P. falciparum infections. For asymptomatic patients who had negative blood smears but were positive by the non-quantitative nested PCR screen, the median parasite density derived from nested qPCR was 220 parasites/ $\mu$ l (interquartile range, 3.6-5100).

\section{Correlation of calculated parasite densities in independently validated $P$. falciparum DBS samples}

Calculated parasite densities for 8 external DBS samples determined using our nested qPCR assay strongly correlated with values determined by an independent qPCR assay [15] (Pearson's r 0.99, 95\% CI [0.96 - 1.0], $P<0.0001$ ).

\section{Discussion}

Accurate quantification of low-density parasitemia from DBS samples has become increasingly important in clinical studies of malaria in which the kinetics of early or treated infection are approximated and for the identification of submicroscopic infections that serve as occult reservoirs for malaria transmission. In contrast to amplification protocols that quantify Plasmodium nucleic acid extracted from cryopreserved blood samples, which have a sensitivity of 0.02-0.06 parasites/ $\mu$ l [4], protocols employing direct qPCR of parasite gDNA extracted from clinical DBS samples typically cannot quantify samples with $<5$ parasites/ $\mu \mathrm{l}[10,14]$. Nested $q \mathrm{PCR}$, in which the product of the initial conventional PCR is used as the template for a second amplification with quantitative real-time PCR, has been used successfully to increase assay sensitivity in the diagnosis of tuberculous meningitis [16], respiratory viruses [17] and, more recently, Plasmodium infection [18].

In this report, a qPCR-only approach was directly compared to nested qPCR using standard curves generated with gDNA from actual clinical DBS samples as well as plasmid DNA. By incorporating a nested amplification with qPCR, the limit of detection was increased by about two orders of magnitude over a qPCR-only approach (Figure 1). However, a conservative estimate of the limit of quantification, and thus the practical sensitivity of the nested $\mathrm{qPCR}$ assay, is $\sim 0.5$ parasites/ $\mu \mathrm{l}$ based on the increased variance at the lowest detectable dilutions and reproducibility with infected standard curves performed by multiple operators. This compares well with the sensitivity of $\sim 2$ parasites/ $\mu$ l in a recent study which also used a nested qPCR approach [18] with the small difference in sensitivity possibly attributable to the amount of whole blood initially used ( $5 \mu \mathrm{l}$ versus $\sim 10 \mu \mathrm{l}$ from three 3-mm punches in this study) and differences in DNA extraction protocols, master mixes, and cycling parameters. Notably, the results here indicate that a $P$. falciparum $18 \mathrm{~S}$ rRNA plasmid-based standard curve can be a reliable option in cases where high-parasitaemia clinical samples are not available, as parasite density estimates from $\mathrm{Ct}$ values are remarkably similar irrespective of whether the standards were prepared from plasmid DNA or gDNA extracted from a clinical DBS sample.

The importance of highly sensitive molecular diagnostics in clinical trials of malaria vaccine and therapeutic candidates and in campaigns to eliminate parasite reservoirs in endemic populations has placed an emphasis on proper standardization and quality assurance of nucleic acid testing protocols $[4,14]$. The strong correlation between parasite densities calculated from the nested qPCR assay described herein with those from an independent protocol [15] provides confidence that the nested $\mathrm{qPCR}$ assay described here generates results that may be directly comparable to other studies using validated qPCR protocols. Furthermore, we also tested our assay over a wide range of parasitaemia from clinical DBS samples to evaluate its utility for field isolates. For patent infections, parasite densities derived from nested qPCR Ct values correlate well with those determined by microscopy both for symptomatic and asymptomatic cases (Figure 3). For submicroscopic infections, qPCR generally overestimates the parasite densities. One possible explanation is that thick blood smears generally underestimate the true parasite density due to parasite loss during staining [19] and, in the case of the highly discordant samples, the loss may have been particularly marked. Another explanation may be reduced precision between replicates due to small volumes of template used in the reactions. One microliter of PCR product was used as the template for the second amplification to maximize the dynamic range of the assay, which allowed quantification of either submicroscopic or high-density parasitaemia using a single protocol. However, if only submicroscopic or low-density parasitaemia is being considered, increasing the template volume for the second 


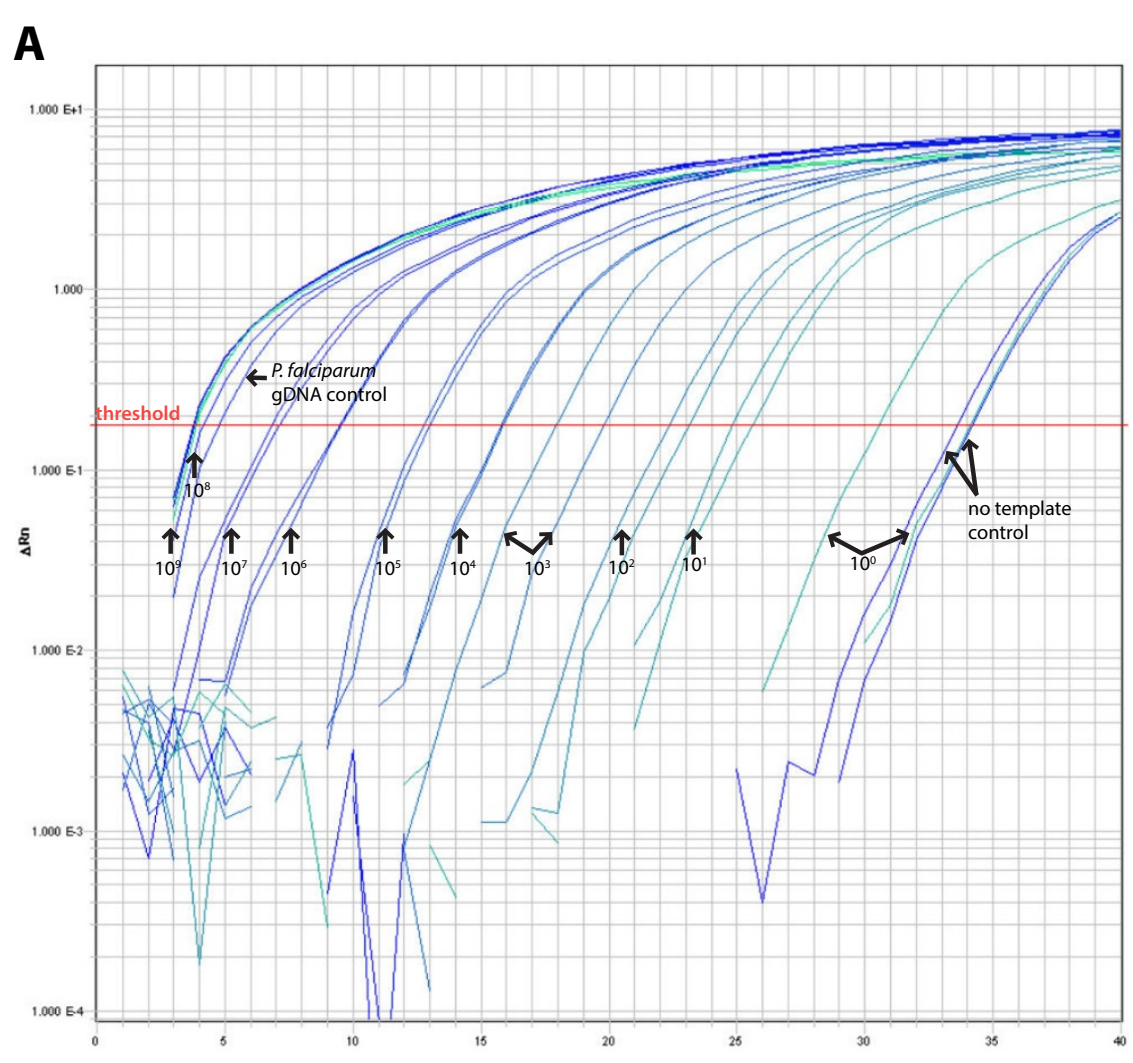

B

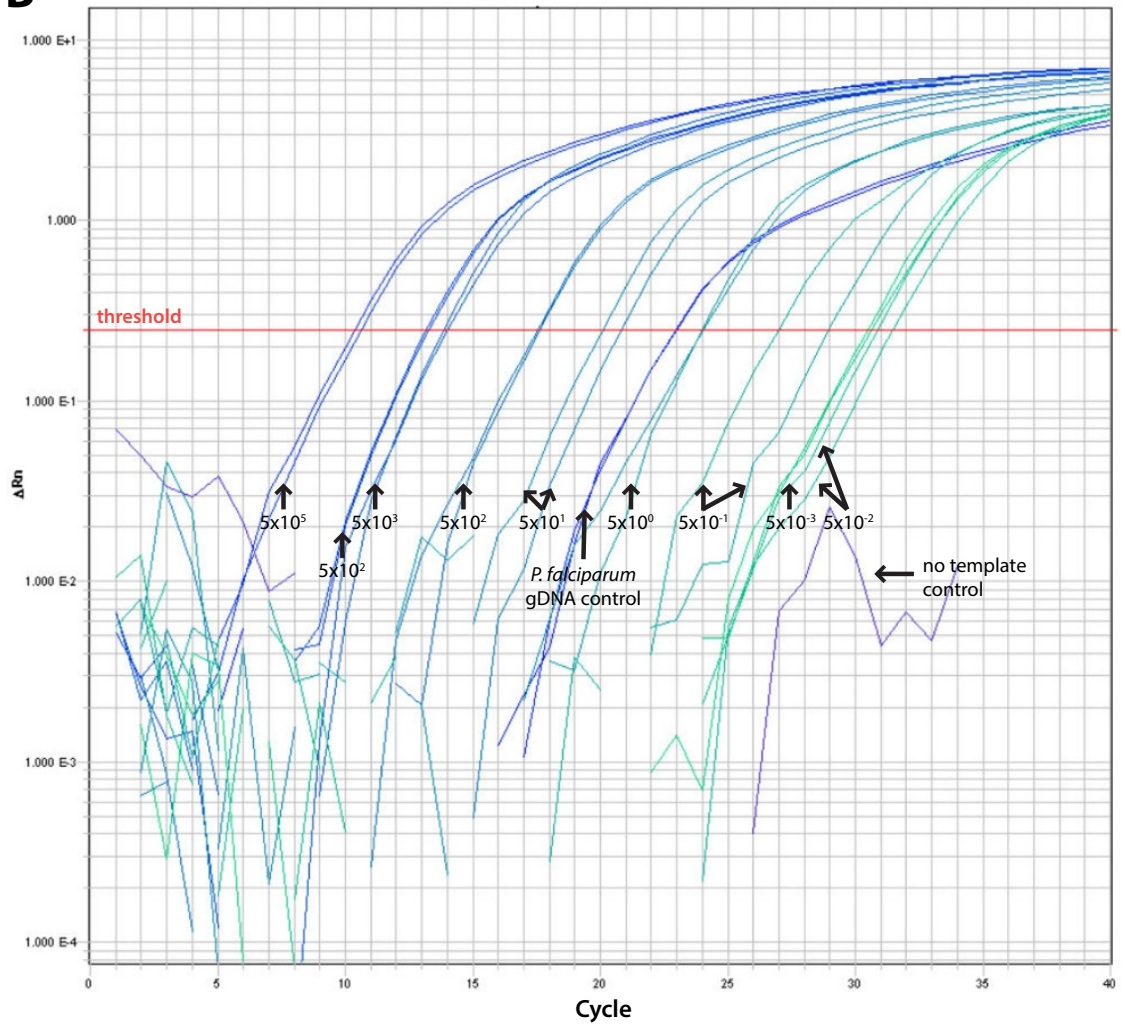

Figure 2 Amplification curves for nested qPCR assay. Nested qPCR amplification curves using 10-fold serial dilutions of (A) P. falciparum 18S rRNA plasmid or (B) gDNA extracted from dried blood spots obtained from a subject with clinical malaria as template DNA (described in the Methods). 


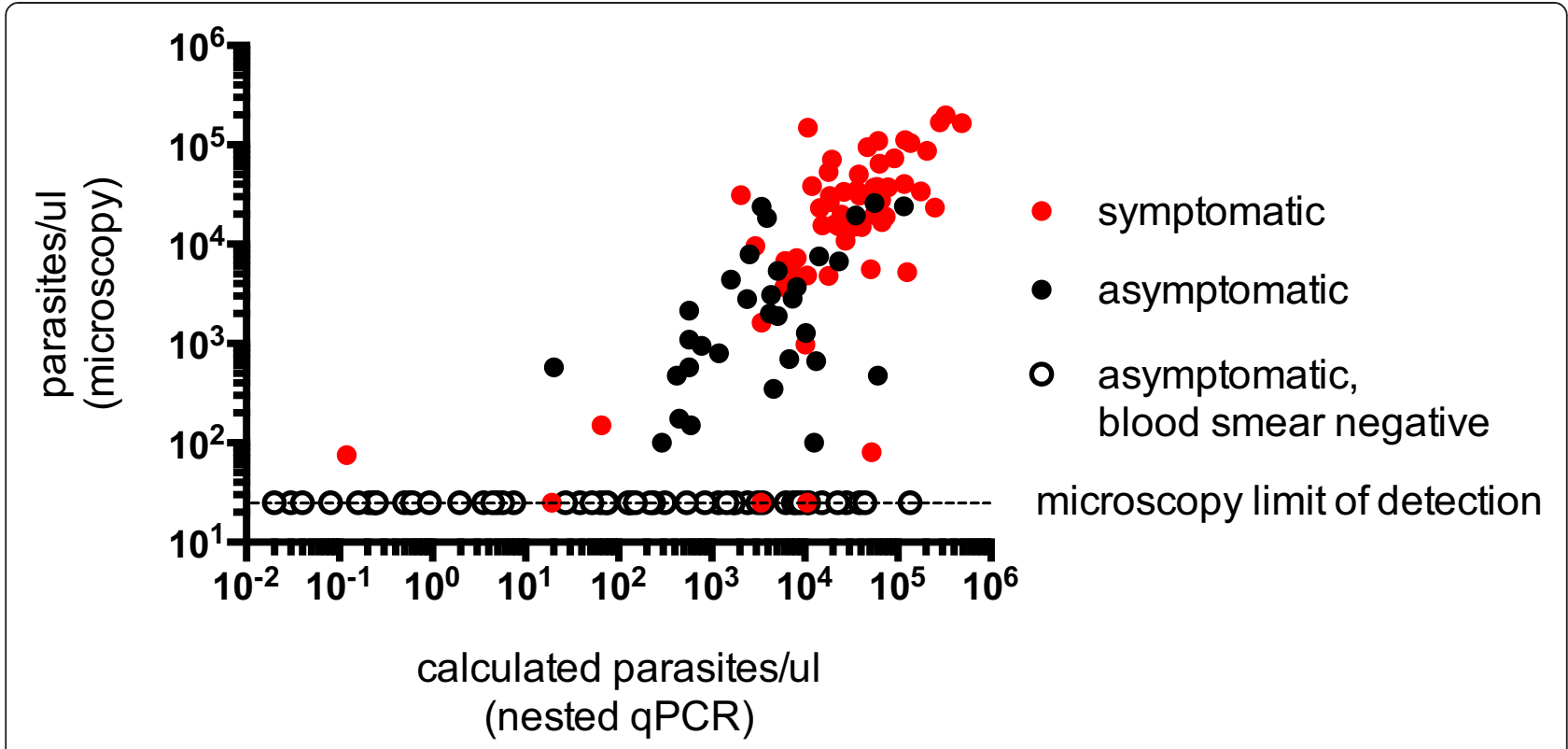

Figure 3 Correlation between parasite densities determined by light microscopy and calculated by nested qPCR. Calculated parasite densities from nested qPCR were plotted against parasite densities determined by light microscopy for symptomatic infections (red circles), asymptomatic infections with positive blood smears (black circles), and asymptomatic infections with negative blood smears (unfilled circles). Parasite densities calculated by nested PCR strongly correlated with both asymptomatic (Pearson's $r=0.58,95 \% \mathrm{Cl}[0.29$ to 0.77$], P<0.001$ ) and symptomatic (Pearson's r 0.70, 95\% Cl [0.53 to 0.81], $P<0.0001)$ P. falciparum infections. The dashed line represents the limit of detection for blood-smear microscopy ( 40 parasites/ $\mu$ ).

amplification may improve not only the precision, but also the sensitivity of the assay. Conversely, on occasion nested qPCR underestimated the parasite density relative to microscopy, but much less frequently (Figure 3). This phenomenon might be explained by the presence of human gDNA interfering with amplification of the parasite gene rather than inefficient DNA extraction, given that appropriate extraction was verified by the presence of human GAPDH.

A major limitation with the nested qPCR approach is the increased chance of false positives given the two cycles of amplification. Thus, care must be taken to reduce the possibility of false positives due to contamination. Of note, amplification curves were occasionally observed to have $\mathrm{Ct}$ values of $>32$ cycles for the negative (no template) control (Figure 2A), but these consistently appear to be primer dimers by dissociation curve analysis (Additional file 1).

Based on these findings, it is recommended that a negative control reaction always be included with the first amplification and that any Ct value within 2 cycles of the negative control be considered negative with additional confirmation by dissociation curve analysis. One way to minimize false positives is to always employ an initial screen for Plasmodium infection using a conventional nested PCR approach (based on the original assay described by Snounou et al. [12]), and selecting only confirmed $P$. falciparum-positive samples for subsequent quantification with nested qPCR as done in this study. This two-step screening approach, although more timeintensive, would also minimize expending qPCR reagents on uninfected samples in malaria surveillance studies.

The nested qPCR approach in this study may be particularly convenient in laboratories that already employ the standard nested PCR protocol developed by Snounou et al. [12] given that the same primer sets are shared between the protocols. Although this assay was only validated for the quantification of P. falciparum parasitemia, applying a nested qPCR approach to the other four human Plasmodium species would be relatively straightforward if species-specific Plasmodium 18S rRNA primers were used during the real-time amplification, as was done in a recent study [18].

\section{Conclusions}

The nested qPCR assay presented here reliably quantifies parasite densities from DBS samples obtained from subjects with asymptomatic and symptomatic malaria and achieves higher sensitivity than a qPCR-only approach. This assay may be useful for active malaria surveillance in areas where submicroscopic asymptomatic infections are prevalent. 


\section{Additional file}

Additional file 1: Nested qPCR dissociation curve for no template negative control and $P$. falciparum gDNA positive control.

\section{Competing interests}

The authors declare that they have no competing interests.

\section{Authors' contributions}

TMT and PDC conceived and designed the study. AO and KK organized and managed the clinical cohort and filter paper samples. SD organized the blood smears and performed the microscopy. TMT, AA, and SL prepared the DNA samples and performed the PCR experiments. TMT, AA, and SL analysed the data. TMT, AA, and PDC wrote the final report. All authors read and approved the final version of the manuscript.

\section{Acknowledgements}

We thank the study participants and research support staff in Kalifabougou and Bamako, Mali. We also thank MR4 for providing the $P$. falciparum $18 \mathrm{~S}$ rRNA PCR plasmid contributed by Dr. Peter A. Zimmerman (Case Western University). Externally validated DBS samples were kindly provided by Dr. Steven M. Taylor (Duke University). The Division of Intramural Research, National Institute of Allergy and Infectious Diseases, National Institutes of Health supported this work.

\section{Author details}

${ }^{1}$ Laboratory of Immunogenetics, National Institute of Allergy and Infectious Diseases, National Institutes of Health, Twinbrook 2, Room 125, 12441 Parklawn Drive, Rockville, Maryland 20852, USA. ${ }^{2}$ Mali International Center of Excellence in Research, University of Sciences, Techniques, and Technology of Bamako (USTTB), BP: 1805 Point G, Bamako, Mali.

Received: 13 June 2014 Accepted: 30 September 2014 Published: 4 October 2014

\section{References}

1. Okell LC, Ghani AC, Lyons E, Drakeley CJ: Submicroscopic infection in Plasmodium falciparum-endemic populations: a systematic review and meta-analysis. J Infect Dis 2009, 200:1509-1517.

2. Murphy SC, Prentice JL, Williamson K, Wallis CK, Fang FC, Fried M, Pinzon C, Wang R, Talley AK, Kappe SH, Duffy PE, Cookson BT: Real-time quantitative reverse transcription PCR for monitoring of blood-stage Plasmodium falciparum infections in malaria human challenge trials. Am J Trop Med Hyg 2012, 86:383-394.

3. malEra Consultative Group on Monitoring E, Surveillance: A research agenda for malaria eradication: monitoring, evaluation, and surveillance. PLoS Med 2011, 8:e1000400.

4. Murphy SC, Hermsen CC, Douglas AD, Edwards NJ, Petersen I, Fahle GA Adams M, Berry AA, Billman ZP, Gilbert SC, Laurens MB, Leroy O, Lyke KE, Plowe CV, Seillie AM, Strauss KA, Teelen K, Hill AV, Sauerwein RW: External quality assurance of malaria nucleic acid testing for clinical trials and eradication surveillance. PloS One 2014, 9:e97398.

5. Douglas AD, Andrews L, Draper SJ, Bojang K, Milligan P, Gilbert SC, Imoukhuede $E B, H i l l$ AV: Substantially reduced pre-patent parasite multiplication rates are associated with naturally acquired immunity to Plasmodium falciparum. $J$ Infect Dis 2011, 203:1337-1340.

6. Bejon P, Andrews L, Andersen RF, Dunachie S, Webster D, Walther M, Gilbert SC, Peto T, Hill AV: Calculation of liver-to-blood inocula, parasite growth rates, and preerythrocytic vaccine efficacy, from serial quantitative polymerase chain reaction studies of volunteers challenged with malaria sporozoites. J Infect Dis 2005, 191:619-626.

7. Andrews L, Andersen RF, Webster D, Dunachie S, Walther RM, Bejon P, Hunt-Cooke A, Bergson G, Sanderson F, Hill AV, Gilbert SC: Quantitative real-time polymerase chain reaction for malaria diagnosis and its use in malaria vaccine clinical trials. Am J Trop Med Hyg 2005, 73:191-198.

8. Hermsen CC, Telgt DS, Linders EH, van de Locht LA, Eling WM, Mensink EJ, Sauerwein RW: Detection of Plasmodium falciparum malaria parasites in vivo by real-time quantitative PCR. Mol Biochem Parasitol 2001, 118:247-251.
9. Tran TM, Li S, Doumbo S, Doumtabe D, Huang CY, Dia S, Bathily A, Sangala J, Kone Y, Traore A, Niangaly M, Dara C, Kayentao K, Ongoiba A, Doumbo OK, Traore B, Crompton PD: An intensive longitudinal cohort study of Malian children and adults reveals no evidence of acquired immunity to Plasmodium falciparum infection. Clin Infect Dis 2013, 57:40-47.

10. Taylor SM, Juliano JJ, Trottman PA, Griffin JB, Landis SH, Kitsa P, Tshefu AK Meshnick SR: High-throughput pooling and real-time PCR-based strategy for malaria detection. J Clin Microbiol 2010, 48:512-519.

11. Mehlotra RK, Lorry K, Kastens W, Miller SM, Alpers MP, Bockarie M, Kazura JW, Zimmerman PA: Random distribution of mixed species malaria infections in Papua New Guinea. Am J Trop Med Hyg 2000, 62:225-231.

12. Snounou G, Viriyakosol S, Zhu XP, Jarra W, Pinheiro L, do Rosario VE, Thaithong S, Brown KN: High sensitivity of detection of human malaria parasites by the use of nested polymerase chain reaction. Mol Biochem Parasitol 1993, 61:315-320.

13. Smith PH, Mwangi JM, Afrane YA, Yan G, Obbard DJ, Ranford-Cartwright LC, Little TJ: Alternative splicing of the Anopheles gambiae Dscam gene in diverse Plasmodium falciparum infections. Malar J 2011, 10:156.

14. Taylor SM, Mayor A, Mombo-Ngoma G, Kenguele HM, Ouedraogo S, Ndam NT, Mkali H, Mwangoka G, Valecha N, Singh JP, Clark MA, Verweij JJ, Adegnika AA, Severini C, Menegon M, Macete E, Menendez C, Cistero P, Njie F, Affara M, Otiena K, Kariuki S, ter Kuile FO, Meshnick SR: A quality control program within a clinical trial consortium for PCR protocols to detect Plasmodium species. J Clin Microbiol 2014, 52:2144-2149.

15. Rantala AM, Taylor SM, Trottman PA, Luntamo M, Mbewe B, Maleta K, Kulmala T, Ashorn P, Meshnick SR: Comparison of real-time PCR and microscopy for malaria parasite detection in Malawian pregnant women. Malar J 2010, 9:269.

16. Takahashi T, Tamura M, Asami Y, Kitamura E, Saito K, Suzuki T, Takahashi SN, Matsumoto K, Sawada S, Yokoyama E, Takasu T: Novel wide-range quantitative nested real-time PCR assay for Mycobacterium tuberculosis DNA: development and methodology. J Clin Microbiol 2008, 46:1708-1715.

17. Perrott P, Smith G, Ristovski Z, Harding R, Hargreaves M: A nested real-time $P C R$ assay has an increased sensitivity suitable for detection of viruses in aerosol studies. J Appl Microbiol 2009, 106:1438-1447.

18. Canier L, Khim N, Kim S, Sluydts V, Heng S, Dourng D, Eam R, Chy S, Khean C, Loch K, Ken M, Lim H, Siv S, Tho S, Masse-Navette P, Gryseels C, Uk S, Van Roey K, Grietens KP, Sokny M, Thavrin B, Chuor CM, Deubel V, Durnez L, Coosemans M, Menard D: An innovative tool for moving malaria PCR detection of parasite reservoir into the field. Malar J 2013, 12:405.

19. Bejon P, Andrews L, Hunt-Cooke A, Sanderson F, Gilbert SC, Hill AV: Thick blood film examination for Plasmodium falciparum malaria has reduced sensitivity and underestimates parasite density. Malar J 2006, 5:104.

doi:10.1186/1475-2875-13-393

Cite this article as: Tran et al:: A nested real-time PCR assay for the quantification of Plasmodium falciparum DNA extracted from dried blood spots. Malaria Journal 2014 13:393.

\section{Submit your next manuscript to BioMed Central and take full advantage of:}

- Convenient online submission

- Thorough peer review

- No space constraints or color figure charges

- Immediate publication on acceptance

- Inclusion in PubMed, CAS, Scopus and Google Scholar

- Research which is freely available for redistribution 